\begin{tabular}{c} 
International Journal of Engineering \& Technology, $7(2.7)(2018) 316-319$ \\
International Journal of Engineering \& Technology \\
SPC \\
Website: www.sciencepubco.com/index.php/IJET \\
Research Paper \\
\hline
\end{tabular}

\title{
Implementation of IoT based smart street light intensity control system using IR and LDR sensors
}

\author{
Suchismita Debata ${ }^{1}$ *, Rupa Mantoliya ${ }^{1}$, Veena Sahithi ${ }^{1}$, Venkata Ratnam Kolluru ${ }^{2}$ \\ ${ }^{1}$ Dept. of Electronics and Computer Science Engineering, KLEF, Vaddeswaram \\ ${ }^{2}$ Associate Professor, Department of Electronics \& Computer Engineering, KLEF, Vaddeswaram \\ *Corresponding author E-mail: suchismitadebata@gmail.com
}

\begin{abstract}
This research article gives an idea about advancements in energy saving of street lights and to reduce the power consumption. The programming terminology for building up the product to the Arduino board at long last, the framework has been effectively outlined and executed. Mainly using two sensor IR and LDR sensor to implement intensity control of street light.IR sensor is use to detect the motion of the objects and LDR (light dependent resistor) used to recognize day-evening. When light falls on the LDR depending on resistance of light the intensity of light is decreased or increase. The street light is automatically ON in evening 6pm and OFF till morning. Through mobile app also we can operate the street light. Using Arduino board for implementing the intensity control of street light.
\end{abstract}

Keywords: Arduino; IR Sensor; LDR Sensor; Streetlight.

\section{Introduction}

Now a days, the people have changed to be unreasonably involved, and did not, make it incomprehensible to find time indeed to switch on the lights at whatever point fundamentally. Smart Street light is robotized framework. The planning another framework for the streetlight don't expend more power. This spared power can be utilized as a part of some different applications, for example, in the water system, towns, towns and numerous different fields. We can outline smart frameworks by utilizing Arduino to control a power of road lights. In this task road lights are planned such that it consequently turns ON and OFF in view of the Light Dependent Resistor (LDR) sensor. The LDR sensor additionally controls the power of light naturally in light of the development of vehicle it darkens and lights up. The development of vehicle is distinguished by the Passive Infrared (PIR) sensor. The proposed framework utilizes the most recent innovation LED lights rather than general lights. The LED innovation is favored over alternate lights in light of the fact that a LED light spares the vitality because of the high current radiant and up keep cost is low, the existence of LED is long and so on. The lights that we utilize by and by depending on the gas release. Consequently, the force of these lights isn't con-trollable. This framework guarantees to give the perfect measure of light where and when required. Poor lighting can cause mis-chances. Use of Energy proficient innovations can diminish the cost of the road lighting definitely and furthermore give amazing effectiveness. The exhibit design is the presentation of computeri-zation and inaccessible organization answers for control road lighting. There are particular sums of control technologies and strategies in controlling the road light framework, for occasion, format, and execution of CPLD based daylight based control saving system for street lights and modified action controller plan and fabricate of customized street light control framework, modified road light control and street thriving module utilizing inserted structure, customized road light control structure, Brilliantly Road Lighting Framework Utilizing
Gsm , imperativeness utiliza-tion sparing courses of action in point of view of careful road lighting control structure and A Novel Plan of a Programmed Lighting Control Framework for a Remote Sensor Organize with Expanded Sensor Lifetime and Decreased Sensor Numbers. In this paper for the most portion we are utilizing two sorts of sensor LDR which moves as illustrated by the degree of light falling on its surface, this gives an affirmations for whether it is a day even-ing, and IR sensor is set for the street, which can be controlled by microcontroller. The IR sensor will be induced fair on the night. at the point when challenge crosses the IR column, a specific light will be ordinarily ON. By utilizing this as a crucial regulate, the savvy framework can be arranged for the idealize utilization of streetlights in anyplace. In this manner, the examination work features the vitality proficient arrangement of the road lights framework utilizing LED lights with IR sensor interface for controlling and overseeing.

\section{Related work}

Suganya et al proposed [1] around Road Light Gleam on recognizing vehicle advancement utilizing the sensor that employment the most recent headway for wellsprings of light as Driven lights. It is in like way utilized to control the exchanging of road light hence as appeared by the light vitality to make stream based energetic control estimations utilizing infrared divulgence headway and keep up inaccessible correspondence among lamppost and control terminal utilizing ZigBee Remote convention. It is like way joins assorted headways: a clock, a bit of information of improvement stream degree, IR, LDR Driven, control transistors. Padmadevi et al implemented the Road Lighting Framework for the purpose of transport developments [2]. This structure functions in the pro-grammed which manages with the streetlamps compatible to quality and shadowiness count and brightness. The control can be made by the common gathering. It wires period cutouts compel and a custom- 
ized control chart for sparing more unmistakable control. The aggregate undertaking is realized utilizing a PIC mi-crocontroller Srikanth et al suggested a ZigBee situated farther oversight programmed Road Lamp Framework [3]. The structure is portrayed out the offer assistance of ZigBee integrated parts which colleagues in recognizing erroneous luminous and used to help in control of brightness coming from that light and also looks at around a watchful framework that takes customized choice for ON/OFF/DIMMING mulling over the transport progression or walker and besides the encompassing condition. PIR advancement sensor is utilized to see a progression of both living and non-living things. Abhishek et al executed the course of action of advance-ment stream based road light control framework [4] with persuad-ing utilization of sun controlled essentialness of the year 2015. It utilizes the viable wellspring of essentialness in the form of sun based control for road brightness. In addition, they utilized the 8052 course of activity micro-controller and conveying the sup-planting commonplace globules along the LEDs in light of which the control utilize is decreased by three times. Sensors will be on both sides of the street which recognizes the transport advance-ment and send the charges to the micro-controller to slaughter $\mathrm{ON}$ the lights. Then from there all the road lights remain slaughtered and it shimmers precisely when it recognizes the motor enhance-ment. In this way, due to the microcontroller, in spite of when its night the lights are slaughtered. Bhuvaneswari et al isolated the road light with an auto taking framework [5] by which one can fabricate the alter productivity of the sun based control age. Here, the sun taking after a sensor is the recognizing gadget which rec-ognizes the location of the sun time to come and gives the regard the intensifier in a viewpoint of a light thickness of sun. Sun tak-ing after a sensor is LDR, enhancer unit is utilized to open up the LDR signals which change over moo matched momentous to un-ordinary state signals and then comparator is given to abdicate. The IC LM324 is utilized as a speaker. Here AT89C51 micro-controller takes the signs and task from Comparator.

\section{Proposed methodology}

The Smart road light control structure handles an energetic control approach. As indicated by the proposed design, at first when it ends up noticeably dim, all the road lights naturally gleam. Taking a cluster of LEDs where-as dividing it into two portions in one section. One is inner section LEDs and other outer section LEDs, for inner section LEDs there is fixed intensity (in dimming state) and outer section LEDs is varies depending on the intensity of car headlights.

\subsection{Existing system}

An industry of road lighting structures is developing quickly and is complex with the fast headway of production and urban bunches. Robotizations, oversight utilize and Taken a toll Possibility are the basic contemplations in the display field of contraptions and power related headways. To command and keep up tangled road fulmination framework more financially, uncommon road light rule structures are made. These frameworks are made to oversight and decrease essentialness utilization of a township open fulmination structure utilizing unmistakable propels. The display work is done utilizing Stowed away lights. At the show time, the Covered up is utilized for urban road light in point of view of administering of gas release, in this way the control isn't commanded by any volt-age decreasing strategy as the release way is broken. Covered up lamps are kinds of electrical gas release light which makes light by techniques for an electric turn between tungsten terminals housed interior translucent or clear consolidated quartz or solidi-fied alumina circular parcel tube. This tube is stacked with the two gas and metal salts. The gas underpins the circular sections cov-ered up the strike. Once the twist is begun, it warms and scrambles the metal salts shaping plasma, which especially develops the control of light passed on by the indirect segment and decreases its essentialness utilize. High-drive release lights are a kind of circu-lar segment light. Disadvantages of Existing System:

- HID lights eat up more control.

- The lifetime of the Covered up lights is less.

- It can't be utilized as a piece of each exterior application.

- Brightness of the lights in the back see mirrors which cause an issue for drivers sometime recently your transport

\subsection{Proposed system}

Though the HID are also not smart and strong so, instead of HID lamp we are taking LEDs. As it having long life time and low cost. In the present field of devices and are truly based on electrical related advances, production of roadway lamping structures are promptly grown and show up the involved quick improvement of production and urban groups. To limit them and keep them up in a complex street lighting structure over a financially, unique street lamps and constraint systems are made. These are made to check and reduce the essentialness usage of a town's open fulmination structure using particular advances which uses Infrared development sensors to recognize the motor improvement after which the street lamps begin to glimmer. As the motor steps, the street lamp was glimmering turns off and then going with lights begins to sparkle. For IR sensor taking serial port value up to 0 to 9600 . Between this value the IR sensor works. LDR sensor works de-pending upon the resistance of the light.

As evening time traffic is more so depending on resistance light the intensity of light is increase or decrease. We can save power up to some extend $(45 \%)$. In midnight time traffic less so we can save more power compare to evening time $(60 \%)$. Through mobile app also can operate street light. Alternate Street light can ON when there is no traffic so that we can save power. When there is traffic as usual the process is done. Here using Ar-duino programming language as it make easier compare to rasp-berry pi board. Below have brief explanation about Arduino Uno board IR and LDR sensor.

a) Arduino Uno R3

Arduino Uno R3 determinations are AT-mega328 micro-controller, working volts at $5 \mathrm{v}$, where input volts changes between 7 to $12 \mathrm{v}$, input voltage compels up to $20 \mathrm{v}$, moved I/O pins 14 , clear pins 6 , DC current $40 \mathrm{~mA}$, streak memory $32 \mathrm{~KB}$ checking $0.5 \mathrm{~KB}$ utilized by the boot loader. SRAM of $2 \mathrm{~KB}$, EEPROM of $1 \mathrm{~KB}$ and clock speed of $16 \mathrm{MHz}$ a parcel of the Highlights of Arduino UNO are control: can be USB affiliation or outside control supply, with 7 to 12 volts endorsed. The Arduino UNO gives control pins to diverse contraptions, the combinations are $5 \mathrm{v} 3.3 \mathrm{v}$ and in IOREF follow to optional control. Arduino Uno is a $2 \mathrm{~KB}$ of SRAM and $1 \mathrm{~KB}$ of EEPROM (Electrically Erasable Programmable Perused As it were Memory). There are different information and abandon pins where 14 of them are computerized pins with serial exchange and outside avoids and PWM (Beat Width Change) pins and 6 clear pins. Arduino changes from all the past sheets which do not utilize the FTDI USB-to-serial driver chip.

\section{b) LDR sensor}

Light dependent resistor (LDR) which shifts as illustrated by when the degree of light falls on its surface, this gives whether it is a dayevening time. The hypothetical thought of the light sensor lies behind, which is utilized as a parcel of this circuit as a need of definition pioneer. LDR is a resistor as a peered up and its confirmation shifts as appeared by the degree of light falling on its surface. At the point when the LDR recognize light, its affirmation will get diminished, along these lines on the off chance that it recognizes need of definition its affirmation will increment

\section{c) IR Sensor}

An infrared sensor is an electronic gadget that ex-udes with a particular conclusion objective to identify few parts of the environment. IR sensor can measure warmth of an address and recognize the action. These sorts of sensors can measure fair infra-red radiation, instep of transmitting it that is called as a withdrawn IR sensor. For the most part in the infrared run, each one of the articles exudes a few sort of warm radiations. These sorts of radia-tions cannot visible in our eyes that can be recognized by an infra-red sensor. The 
maker is fundamentally an IR Driven and the pointer is basically an IR and photodiode which is sensitive to the IR light of a vague wavelength from that released by IR Driven. At that point when Infrared light falls on photodiode, then the securities and surrender voltages are alter in a degree to the enor-mity of the Infrared light got.

\section{Working principle}

Manual controlling the system. In this paper, two sorts sensors will be utilized which is the light sensor like LDR and IR sensor. The light distinguished will distinguish shadowiness to start the ON/OFF switch, so the streetlights will be set up to turn on and the IR sensor will see the enhancement to prompt the streetlights. LDR, which changes agreeing to when the degree of light falls on its surface, this gives enrolments for whether it is a day or night. The IR sensor will be authorized fair in the night. In case any re-quest crosses the IR bar, a specific light will be subsequently ON. The lighting framework incorporates Arduino board, LDR, IR sensor and other electrical supplies. Cluster of LEDs were divided into two portion middle section and outer section. middle section LEDs having fixed intensity(in dimming state) and outer section LEDs varies according to the light that falls on LDR.At the point when a power of light is high then protection is low, when a force of light is low then the protection is high. The process is continu-ous, and the data has been saved with cloud.

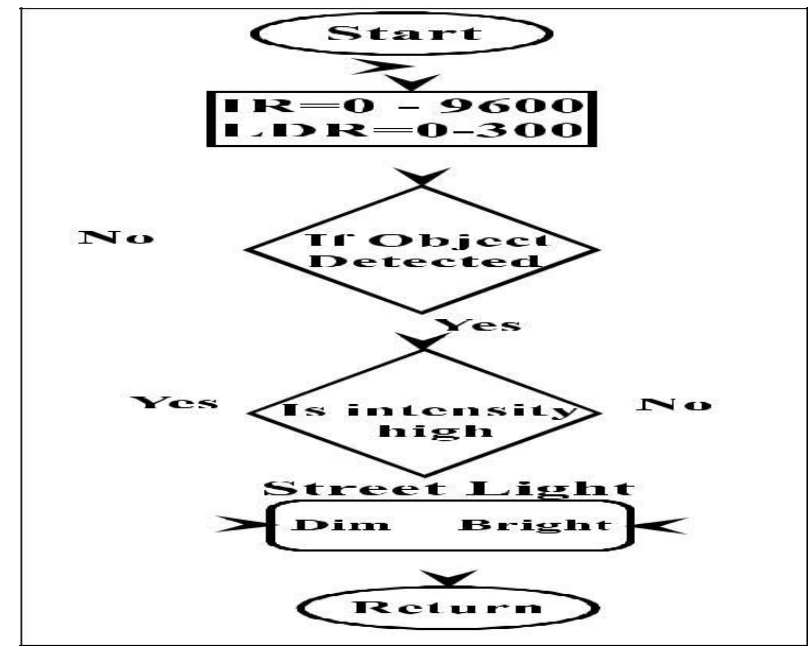

Fig. 1: Flow Chart of Intensity Street Light.

As you studied in above proposed system about the IR sensor and LDR sensor range and how it works. IR sensor connected to the microcontroller in the Arduino board. In the Arduino board you will connect some pin number 2, 47,12 and one Analog pin A0we are taking Analog pin and 4 pin as input pin and remaining pin as output pin .that were connected to LEDs as output pins. For IR sensor taking some serial port values up to 0 to 9600 . Between these values the IR sensor works. When traffic is more we can save power to some extends $(45 \%)$. And when traffic is less we can ON alternate lights so that we can reduce the wastage of power. Manually easily operate.

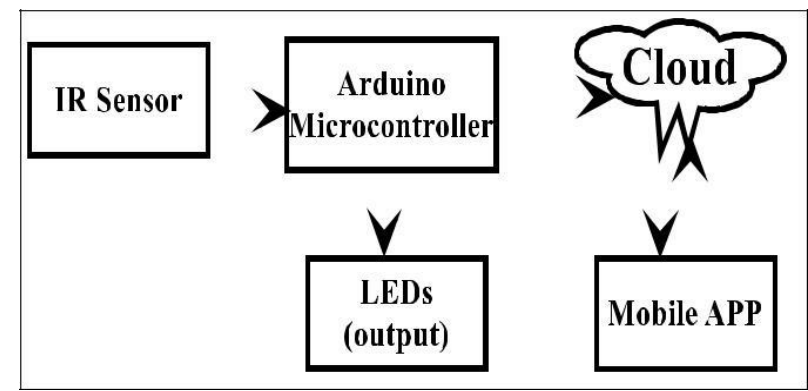

Fig. 2: Block Diagram of Light Intensity Control System.

\section{Results and discussions}

As you see the street light is $\mathrm{ON}$ for every time so that there will be lots of wastage of power so, the main intention of this project is to reduce the wastage of power. Easily operates and cost is low. In this task, the principal development is to set up the information sources and yields of the framework to control the lights of the road. The road light will be ON in evening and OFF till in morn-ing. LDR and IR sensor plays major role. IR sensor detects the objects and depending on resistance of light the intensity of light is increase or decrease. As evening time traffic is more all the lights glows depending on resistance of light. In midnight as the traffic is less than the light will be in dim. With the help of the above proposed system one can save more power, and that can be implemented and shown the result in Fig. 4. This can be outlined by utilizing Arduino board, LDR sensor, and IR sensor shown in Fig. 5.

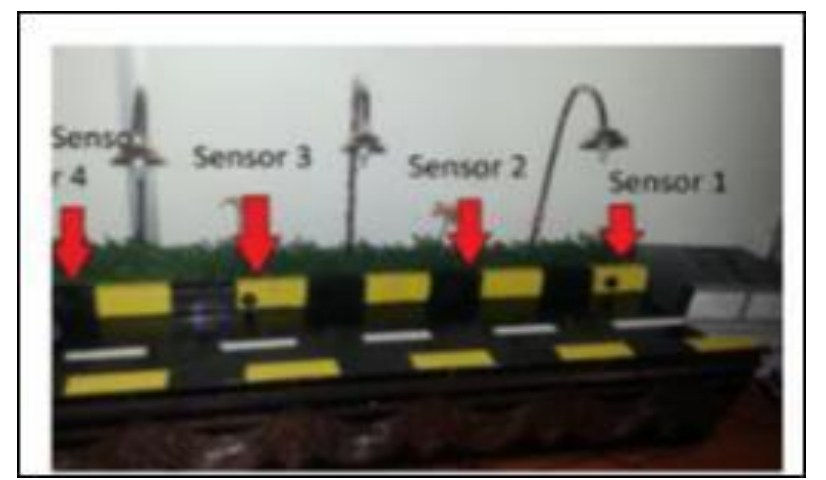

Fig. 3: Prototype of Street Light.

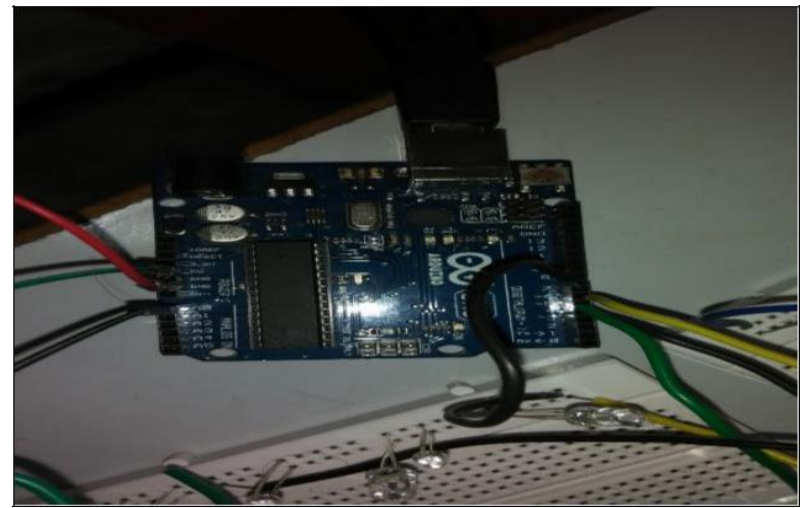

Fig. 4: Photograph of Experimental Implementation with Arduino.

Can save more power (60\%). Through mobile app also can operate the street light. In midnight traffic is less so through mobile app [6] K. Muralidhar,MayanakAgrwal,K.Akashreddy,M.Monica4,E.Ti rumaleswari,design of intelligent street light control system using Low cost AT89C51 microcontroller. Issue 2, February (2017).

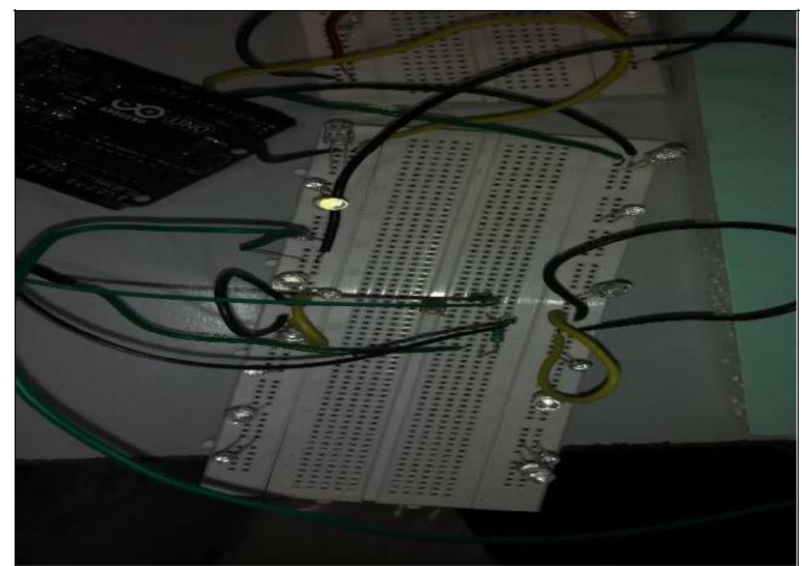

Fig. 5: Experimental Set Up of Street Light Intensity Control. 


\section{Conclusion}

This paper clarifies the arrangement and advancement of Arduino based Driven road light auto control structure circuit. The circuit works fittingly to turn road light Driven ON/OFF. In the wake of outlining out the circuit which controls the power of road light here, LDR sensor and the IR sensors are the two standard sensors working in this circuit. In case the two conditions have been fulfilled the circuit will do the pined for fill in as appeared by the particular program. Each sensor controls the executing ON or the lighting parcel of road light. The control of Road lights has been reasonably controlled by Arduino board. Road lights are a wide buyer of imperativeness for urban bunches utilizing something like 30-half of essentialness investing plan. On the off chance that each city presents the proposed structure by at that point a part of imperativeness can be spared. Proposed framework is a controlled sparing system for driven Road lights by utilizing Arduino Board.

It turns out most strong and time useful way to bargain with switch ON/OFF road lights. It gives a successful degree to spare essentialness by keeping up a key separate from senseless wastage of vitality, caused on account of manual exchanging or lighting of road lights when it isn't required. It handles an energetic control framework for development stream. The proposed framework is particularly fitting for road lighting in inaccessible urban and common regions where the advancement is moo each so regularly. The structure is flexible, extendable and completely versatile to client needs

\section{References}

[1] S. Suganya, R. Sinduja, T. Sowmiya and S. Senthilkumar, Street light glow on detecting vehicle movement using sensor.

[2] S. Padmadevi and K. SanthaSheela. "Survey on street lighting system based on vehicle movements." Int. J. Innov. Res. Sci., Eng., Tech 3, no. 2 (2012).

[3] Steve Chadwick, "Street Light Monitoring-a Practical Solution magazine" November/December 2002.

[4] M.Abhishek, Syedajram shah, K.Chetan, K. Arun Kumar, Design and implementation of traffic flow based street light con-trol system with effective utilization of solar energy, International journal of Science Engineering and Advance Technology, IJSEAT, Vol 3, Issue 9, September -2015.

[5] C.Bhuvaneshwa, R.Rajeswari, C. Kalaiarasan "Analysis of Solar energy based street light with auto tracking system", Interna-tional Journal of Advanced Research in Electrical, Electronics and Instrumentation Engineering, Vol 2, Issue 7, July 2013.

[6] K. Muralidhar, MayanakAgrwal, K.Akashreddy, M.Monica4, E.Ti rumaleswari,design of intelligent street light control system using Low cost AT89C51 microcontroller. Issue 2, February (2017). 